Sustainable Structures

ISSN: 2789-3111 (Print); ISSN: 2789-312X (Online)

http://www.sustain-dpl.com/picnews.asp?id=155

DOI: $10.54113 /$ j.sust.2021.000002

ORIGINAL ARTICLE

\title{
Semi-rigid behaviour of stainless steel beam-to-column bolted connections
}

\author{
Mahmud Ashraf ${ }^{\text {a,* }}$, Mohammad Jobaer Hasan ${ }^{\text {b }}$, Safat Al-Deen ${ }^{\text {b }}$ \\ ${ }^{\text {aS }}$ School of Engineering, Deakin University, Geelong Waurn Ponds 3216, Australia.

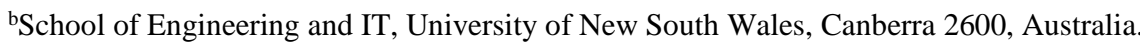 \\ *Corresponding Author: Mahmud Ashraf; Email: mahmud.ashraf@ deakin.edu.au
}

\begin{abstract}
Stainless steel is increasingly used in structural applications but there is still significant lack of experimental evidence on the moment-rotation $(M-\varphi)$ behaviour of moment resisting beam-to-column connections. The current paper presents experimental test results obtained from full scale tests conducted on three widely used connection types i.e., double web angle (DWA), top seat angle (TSA) and top seat with double web angle (TS-DWA) connection. Considered beam, column and angle sections were fabricated using austenitic stainless steel plates and M20 high strength bolts were used for connection assembly. $M-\varphi$ curves for all connections were carefully recorded and were used to determine initial stiffness $\left(K_{\mathrm{i}}\right)$ and moment capacity $\left(M_{20 \mathrm{mrad}}\right)$ for each of the connections. Eurocode 3 guidelines were used to check the classification i.e., whether or not the connections were semi-rigid in nature. Although the considered DWA connection failed to achieve partialstrength, both TSA and TS-DWA connections showed obvious semi-rigid nature despite the connection capacities were limited by bolts. In addition, extensive ductility of stainless steel ensured that all three connection types achieved a minimum connection rotation of $30 \mathrm{mrad}$, which is specified by FEMA as a requirement for earthquake design of ordinary moment frames.
\end{abstract}

Keywords: Stainless-steel; semi-rigid connection; moment-rotation behaviour; beam-to-column connection; full scale test; partially-restrained connection.

\section{Introduction}

Beam-to-column connections are often considered as one of the most critical elements in bare metallic frame construction as the overall structural performance is highly influenced by the connection response. Ordinary steel construction has been dominating the construction field for centuries and significant research evidence are readily available on design, integrity and performance of various structural elements such as beams, columns and connections. Use of stainless steel in structural applications is relatively new. Stainless steel exhibits nonlinear stress-strain response followed by significant strain hardening, which is not appropriately considered in the current design codes, resulting in conservative predictions for member resistances. Emergence of new stainless steel alloys such as duplex and lean duplex offer high strength and corrosion resistance in addition to other obvious advantages of metallic construction [1-3]. Significant research on stainless steel members has been reported in the recent past [4-9], but research on beam-to-column connections is still scarce.

The behaviour of stainless-steel bolted connections under axial loading has recently been reported by several researchers. Experimental and numerical investigations were conducted on cover plate connections made from austenitic grade [10-11]; effect of curling on bolted connections has been 
Ashraf et al, SUST, 2021, 1(1): 000002

investigated through a comprehensive parametric study [12]; experimental and numerical investigations were reported on the effect of net section on connection response and its bearing failure mode [13-14]. Numerical investigations were reported on bolted connections using SS angles and gusset plates [15]. However, all reported research predominantly focused on the in-plane connection resistance and the corresponding failure modes. In recent times, few studies reported investigations on the momentrotation $(M-\phi)$ behaviour of SS beam-to-column connections [16,17]. FE models for stainless steel flange cleat connections were developed based on experimental results reported for carbon steel connections, and analytical models were proposed to capture connection $M-\phi$ behaviour. An experimental study has been reported on small scale specimens for end plate connections with and without extended end plates, and for top-seat connections with and without double web angles [18]; obtained results were later compared against Eurocode 3 [19] guidelines. The effects of combined tension and shear on stainless steel bolts were investigated recently - both experimentally and numerically [20].

Full-scale experimental tests were conducted on three widely used connection types such as double web angle (DWA), top-seat angle (TSA) and top-seat with double web angle (TS-DWA) as part of a recent $\mathrm{PhD}$ research in the University of New South Wales [21]. In addition to full scale testing, extensive parametric analysis was conducted using FE modelling technique and analytical models were proposed to simulate $M-\phi$ behaviour of considered beam-to-column connections. This paper presents an overview of the $M-\phi$ behaviour of all three full scale connection specimens, and assessment of the observed behaviour against Eurocode 3 classification system for semi-rigid behaviour.

\section{M- $\varphi$ behaviour of beam-to-column connections and their classifications}

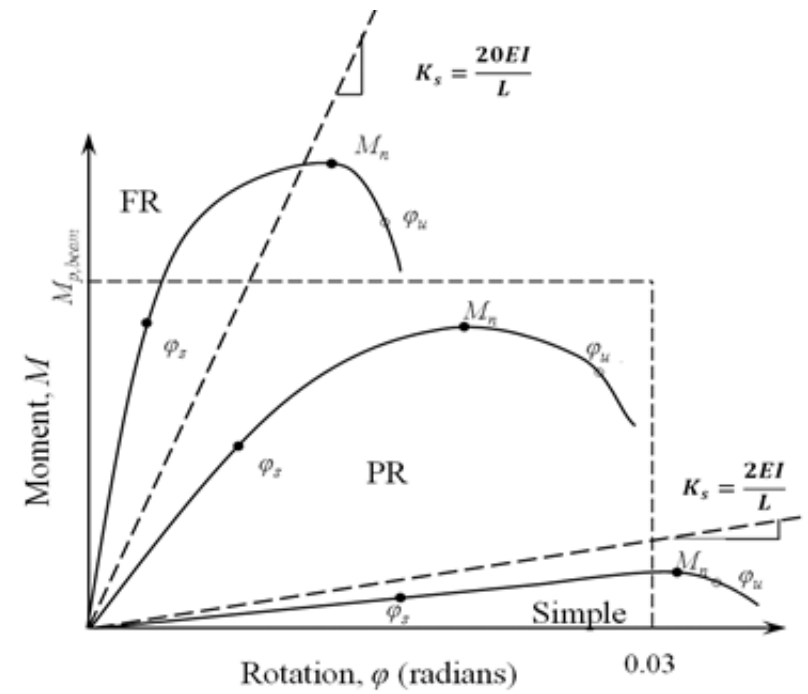

Fig. 1. M- $\varphi$ response of fully restrained (FR), partially restrained (PR) and simple connections [22]

Beam-to-column connections are typically subject to axial force, shear force, and bending moment for its in-plane behaviour. However, the deformations caused by axial and shear forces are usually small when compared to that caused by bending moment. Small deformation typically means it is significantly less than the deformation experienced by the gravity action of bending dominated connections. Since the analysis of semi-rigid connection is a complicated and iterative process, the effect of axial and shear can be neglected to make the structural analysis less cumbersome. However, serviceability limits including lateral sway of structures should be appropriately checked for axial and shear forces to ensure satisfactory performance of structural systems. For practical purposes, only the effect of moment on the rotational deformation of connections is considered in connection classification. Over the last three decades, significant research activities were reported on semi-rigid connections to accurately incorporate this observed behaviour in structural design. $M$ - $\phi$ curves are used to classify connections as simple, semi-rigid or partially restrained (PR) and fully restrained (FR) based on their stiffness, strength and ductility. AISC [22] presents an up-to-date and straightforward classification scheme as shown in 
Ashraf et al, SUST, 2021, 1(1): 000002

Fig. 1, where $M_{\mathrm{p}, \text { beam }}$ refers to the plastic moment capacity of connected beam and $M_{\mathrm{n}}$ refers to the peak nominal moment obtained from test; other symbols used in Fig. 1 are explained in Table 1.

Table 1. AISC requirements for semi-rigid or partially restrained connections [22].

\begin{tabular}{|c|c|c|}
\hline Stiffness & Strength & Ductility \\
\hline $\begin{array}{l}\qquad \frac{2 E I}{L}<K_{s}<\frac{20 E I}{L} \\
\text { where } K_{s} \text { is secant stiffness at } \\
\text { service load, } L \text { and } E I \text { are the } \\
\text { length and bending rigidity of } \\
\text { connected beam, respectively. } \\
\qquad K_{s}=\frac{M_{s}}{\varphi_{s}} \\
\text { where } M_{s} \text { is moment at service } \\
\text { load (N-mm) and } \varphi_{s} \text { is the rotation } \\
\text { at service load (rad). }\end{array}$ & $\begin{array}{l}\text { Must be adequate to resist } \\
\text { moment demand by implied } \\
\text { design loads. } \\
\text { If the moment-rotation response } \\
\text { does not exhibit a peak load, } \\
\text { then strength can be taken as } \\
\text { the moment at a rotation of } 0.02 \\
\text { rad. }\end{array}$ & $\begin{array}{l}\text { Satisfies rotation demand at the } \\
\text { strength limit state or } \varphi_{u}=0.03 \mathrm{rad} \text {. } \\
\text { Rotation capacity } \varphi_{u} \text { can be } \\
\text { calculated rotation corresponds to } \\
\text { connection moment dropped to } \\
0.8 M_{n} \text {. If no loss in strength } \\
\text { observed beyond } 0.03 \mathrm{rad} \text { then } \varphi_{u}= \\
0.03 \mathrm{rad} \text {. }\end{array}$ \\
\hline
\end{tabular}

On the contrary, Eurocode 3 [19] defines connections by their stiffness or strength. Eurocode 3 recommends that rigid frame should be analysed and designed as either braced or unbraced frames. Braced frames are defined as a framing system, which reduces the horizontal displacement by at least $80 \%$. A connection is classified as rigid connection if the initial stiffness $K_{\mathrm{i}}$ obtained from the $M-\phi$ curve meets the following conditions: $\mathrm{K}_{\mathrm{i}}>8 E I_{\mathrm{b}} / L_{\mathrm{b}}$ for braced frames and $K_{\mathrm{i}}>25 E I_{\mathrm{b}} / L_{\mathrm{b}}$ for unbraced frames. However, if $K_{\mathrm{i}}$ is equal or less than $0.5 K_{\mathrm{b}}$, the connection is considered as nominally pinned. Initial stiffness of a connection lying between these two extremes is classified as semi-rigid as shown in Fig. 2. The beam stiffness $K_{\mathrm{b}}$ can be taken as $K_{\mathrm{b}}=E I_{\mathrm{b}} / \mathrm{L}_{\mathrm{b}}$, where $E I_{\mathrm{b}}$ is the flexural stiffness of the beam and $L_{\mathrm{b}}$ is the beam span length.

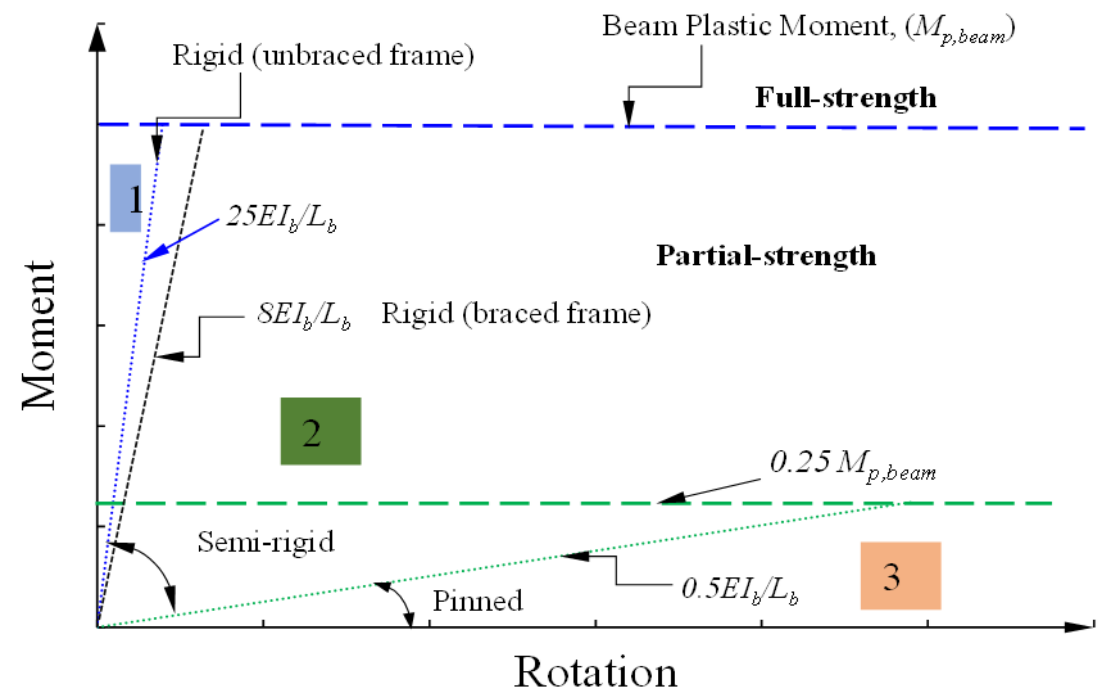

Fig. 2. $M-\varphi$ characteristics of connections according to EC3 [19].

In addition, considering the connection strength, Eurocode 3 [19] specifies three types of connections such as full-strength, partial-strength and nominally pinned connections. If the ultimate moment capacity of the connection $\mathrm{M}_{\mathrm{u}}$ is not less than the beam plastic moment $M_{\mathrm{p} \text {, beam }}$, the connection is classified as a full-strength connection, whereas if $M_{\mathrm{u}} \leq 0.25 M_{\mathrm{p}}$, beam, the connection is classified as nominally pinned connection. When $M_{\mathrm{u}}$ of a connection lies between the limits specified for nominally pinned connection and full-strength connection, the connection is classified as partial-strength (semirigid). Analysis and design of semi-rigid connection is an iterative process, and the strength requirement is not as strict as that for the full-strength connection. The strength of connection may sometimes be higher than those of the connected beams. However, semi-rigid connection must have the rotational capacities that meet rotational demands similar to those for simple connections. These criteria are also true for the interior connections in a structural frame. 


\section{Background of partially restrained (semi-rigid) connection}

Partially restrained (PR) or semi-rigid connections exhibit an intermediate level of rigidity that lies somewhere between a simple shear connection and a fully rigid (FR) moment connection. PR moment connections are permitted upon evidence that the connections to be used are capable of furnishing, as a minimum, a predictable percentage of full end restraint. A beam line approach usually characterises the relationship between the end moment and the end rotation for a given beam. As illustrated in Fig. 3, a simple shear connection has the zero-end moment corresponds to maximum end rotation, however, the FR moment connection shows the fixed-end moment corresponds to a zero end rotation. If the $M-\phi$ curve of the given PR moment connection, for instance - type A or B, are superimposed on the beam line as shown in Fig. 3, the point of intersection of the connection $M-\phi$ curve with the beam line defines the beam end moment and the required strength for which the PR moment connection must be designed. Since the exact location of this intersection point is largely dependent on test results and experience with similar situations, appropriate use of PR moment connections is dominated by the actual or accurately predicted $M-\phi$ behaviour of the connection in consideration.

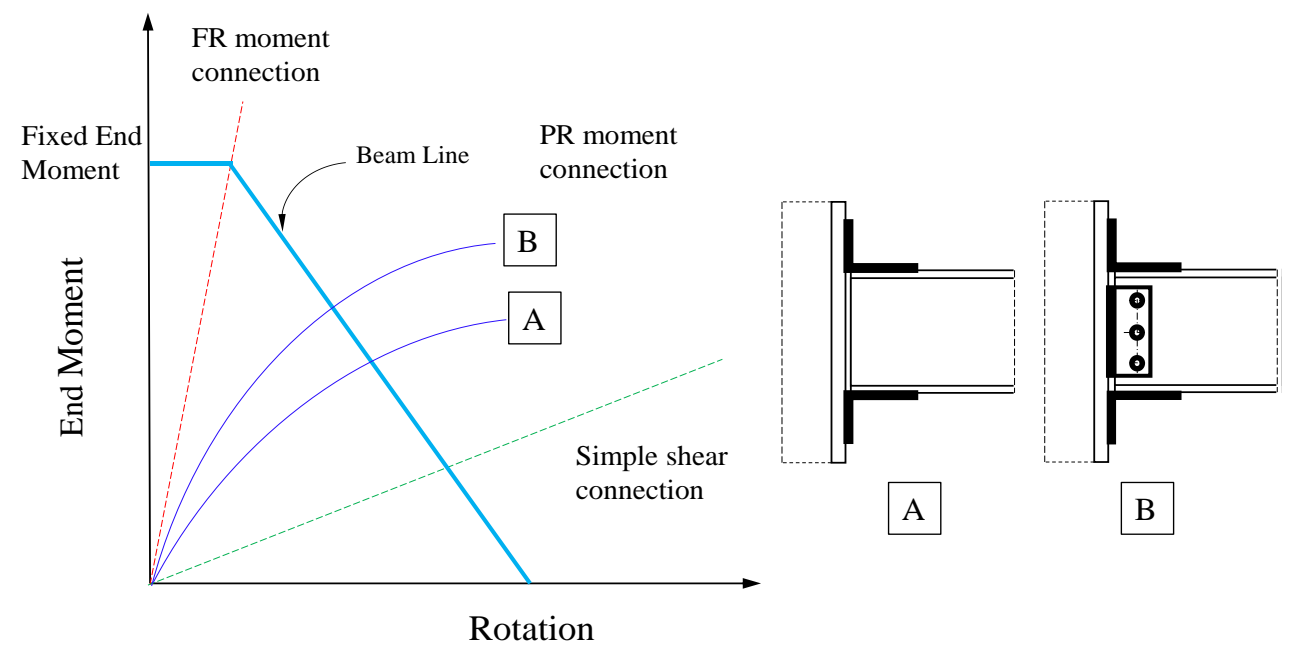

Fig. 3. PR moment connection behaviour [22]

Design guidelines provided by the AISC [22] clearly recommend that design of PR connections would require the $M-\phi$ characteristics, which should then be incorporated into the analysis and member design. Such connections must be designed for the combined effect of moment and shear such that their rotational capacity satisfies the rotational demand at the strength limit state. Typical $M-\phi$ curves for many PR connections are available from one of several databases [23-26] but it is worth noting that the tabulated $M-\phi$ curves should not be readily extrapolated to sizes or conditions beyond those used to develop the database because the failure modes may be significantly different. When the connections to be modelled do not fall within the range of the databases, it may be possible to determine the response characteristics from tests, simple component modelling, or finite element studies from the relevant resources. Accurate knowledge on semi-rigid nature of stainless steel connections would require extensive full scale testing to gather reliable experimental evidence on their $M-\phi$ behaviour. This paper presents one such experimental effort to investigate the $M-\phi$ response of typical beam-to-column connections such as DWA, TSA and TS-DWA connections produced from austenitic stainless steel.

\section{Connection configurations}

Connection components and configurations considered in the current study were similar to those used in widely cited research on carbon steel beam-to-column connections in 1980s [27-29]. Results from these studies have been used in numerous analytical and numerical research related to beam-tocolumn connection. Azizinamini et al. [28] considered a pair of beams connected by a stub column and the load was applied at the centre of the stub column by using a hydraulic actuator of a $254 \mathrm{kN}$ (55 kip) capacity. The overall length of the beam was considered to be $6.10 \mathrm{~m}$ to replicate a typical occupancy in a residential building framing system. The column section was reasonably heavy and compact so that the failure concentrated on the connection element. In the current study, built-up sections resembling 
Ashraf et al, SUST, 2021, 1(1): 000002

the dimensions of AISC sections W14×38 and W12×96 were fabricated using stainless steel plates to act as beam and column respectively. Connecting elements such as angles and bolts were collected from the local stainless steel suppliers. All necessary technical support in fabricating and conducting the experimental tests were provided by the Structures Laboratory at The University of New South Wales, Canberra, Australia.

\subsection{Double web angle (DWA) connection}

DWA bolted connection is composed of two angles, which are used to connect a beam to a column using bolts as fasteners. Fig. 4(a) shows the geometric details of the connection considered in the current study consisting of a $600 \mathrm{~mm}$ long stub column embedded in the ground and a $1200 \mathrm{~mm}$ long beam connected to the column using bolts. Web angles were used to connect the beam web to the column flange. Metric standard M20 austenitic grade bolts with compliant nut and washer were used as fasteners. Fig. 4(b) shows all required geometric details of the DWA connection used in the current study.

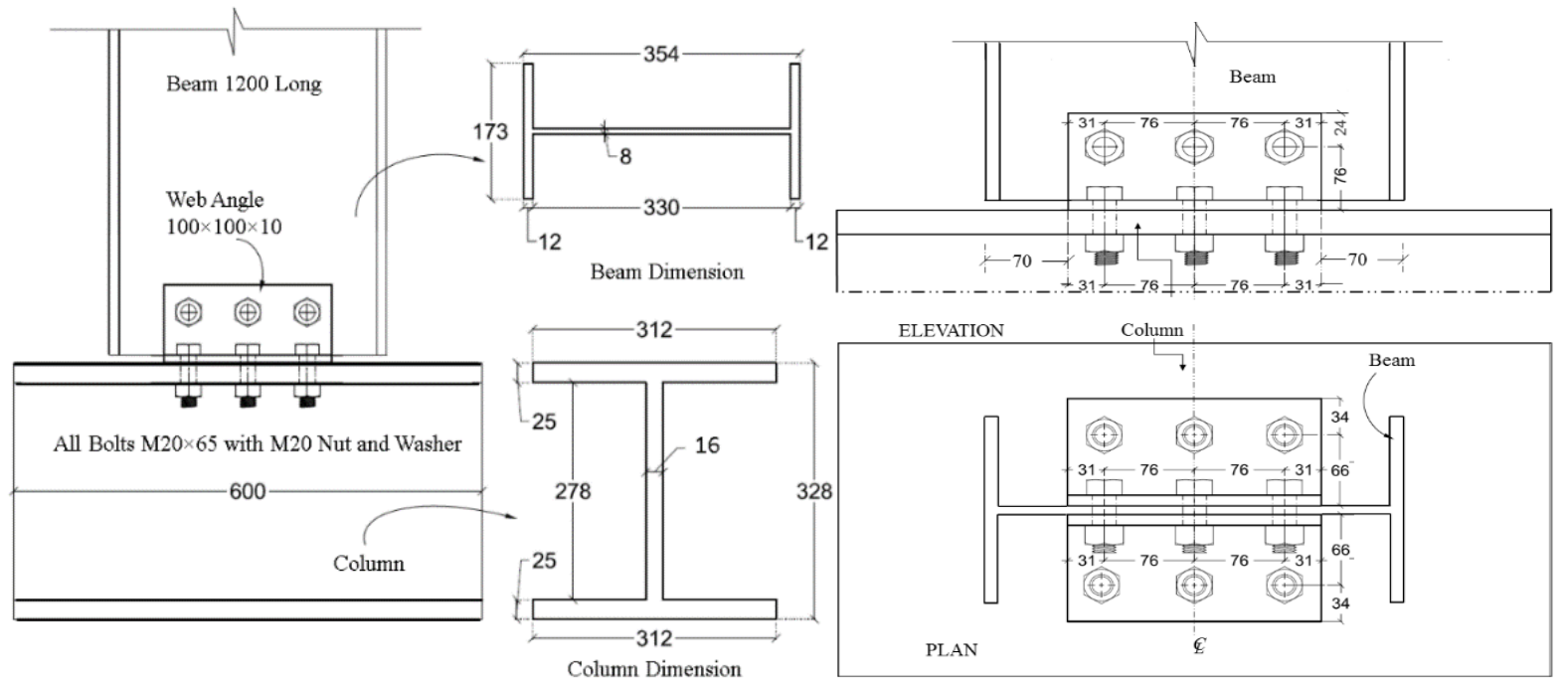

(a) Elements of connection

(b) Bolt spacing in connection

Fig. 4. Geometric details of DWA connection (all dimensions are in $\mathrm{mm}$ ).

\subsection{Top-seat angle (TSA) connection}

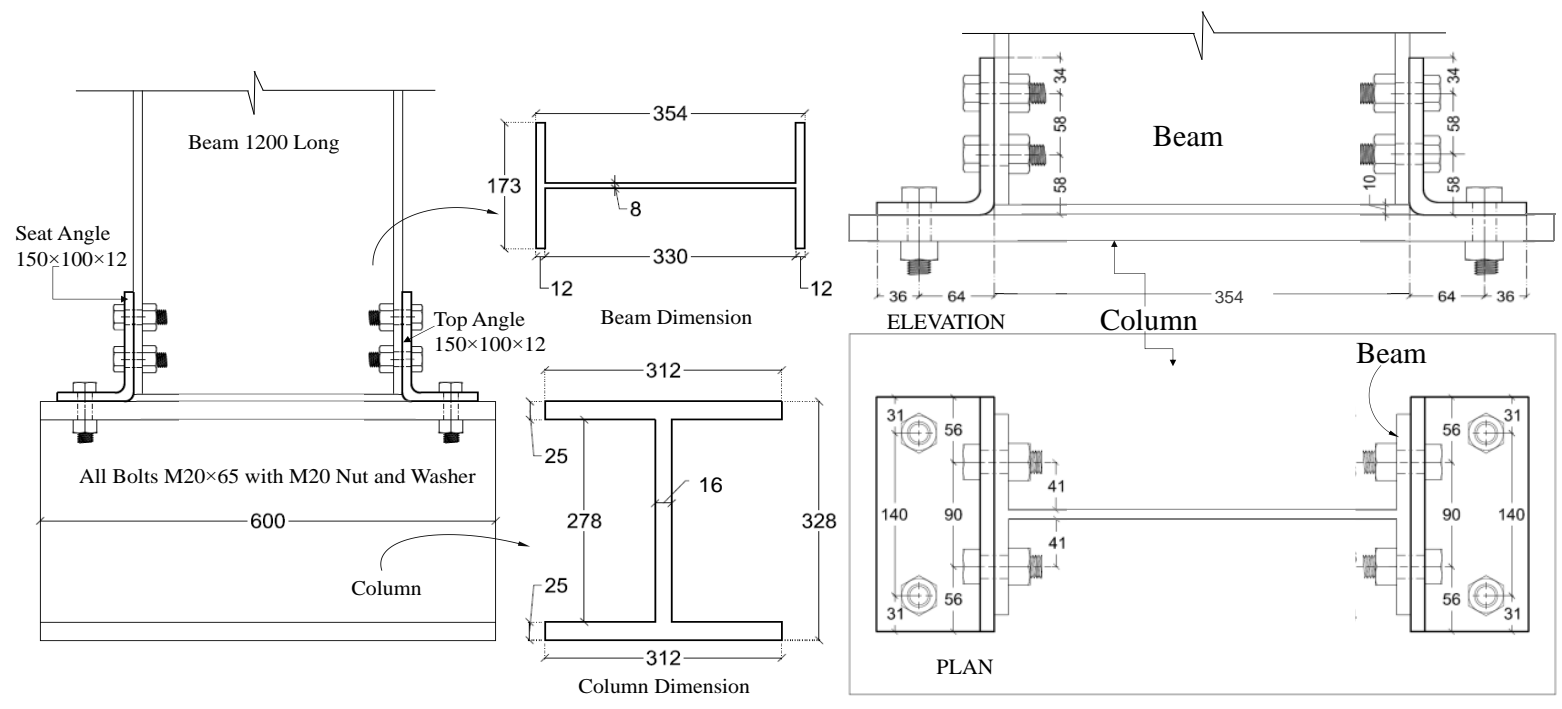

(a) Elements of connection

(b) Bolt spacing in connection

Fig. 5. Geometric details of TSA connection (all dimensions are in $\mathrm{mm}$ ).

TSA bolted connections produced from austenitic stainless steel was composed of two angles that were used to connect the beam flanges to the column flanges using bolts as fasteners. Beam and column 
sections were arranged in such a manner so that the $600 \mathrm{~mm}$ long stub column was fixed at the base and the $1200 \mathrm{~mm}$ long beam was connected to the column using bolts to achieve TSA type connection as shown in Fig 5(a). Metric standard M20 austenitic grade bolts with compliant nut and washer were used as fasteners. Fig 5(b) shows all required geometric details of the TSA connection type used in the current study.

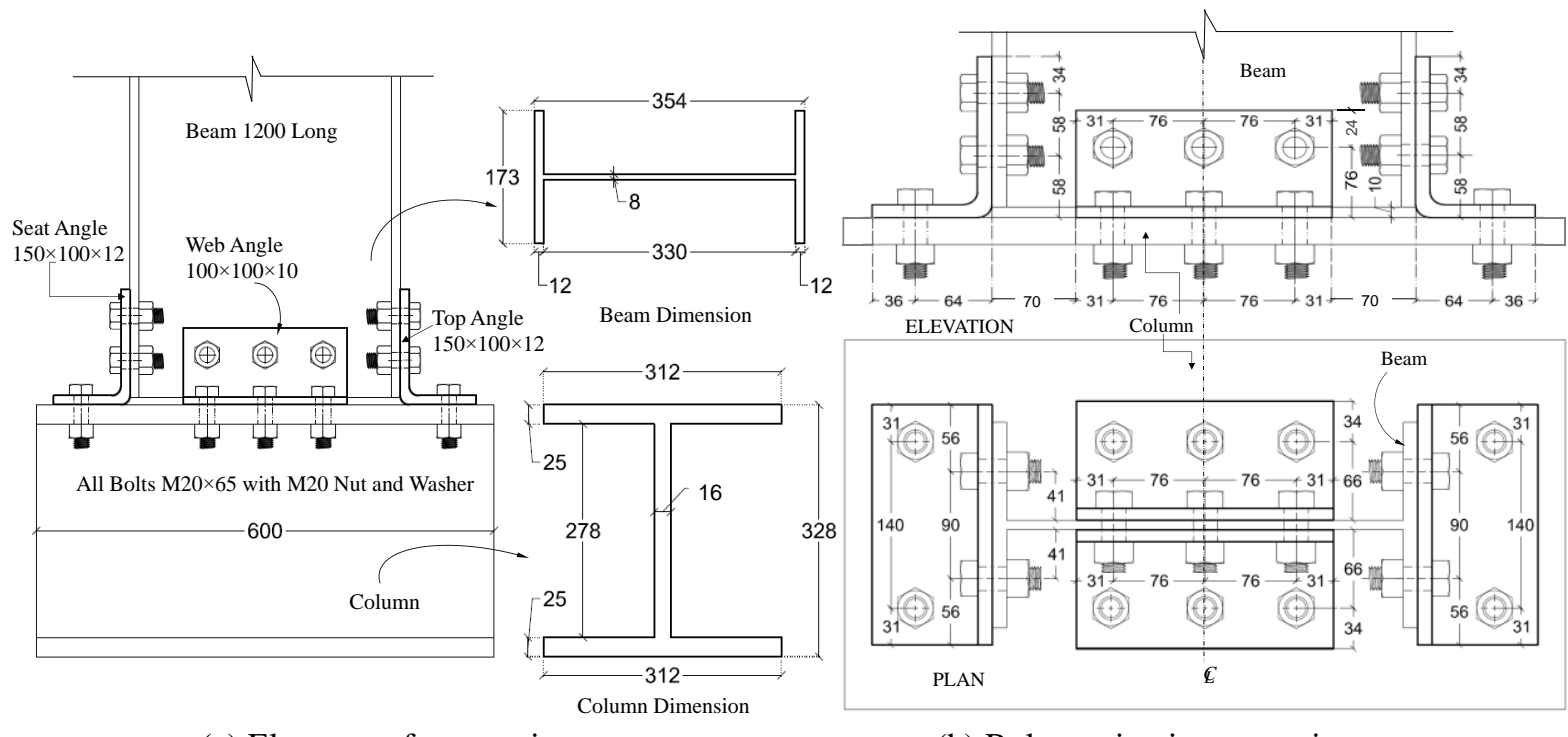

(a) Elements of connection

(b) Bolt spacing in connection

Fig. 6. Geometric details of top-seat with DWA connection (all dimensions are in $\mathrm{mm}$ ).

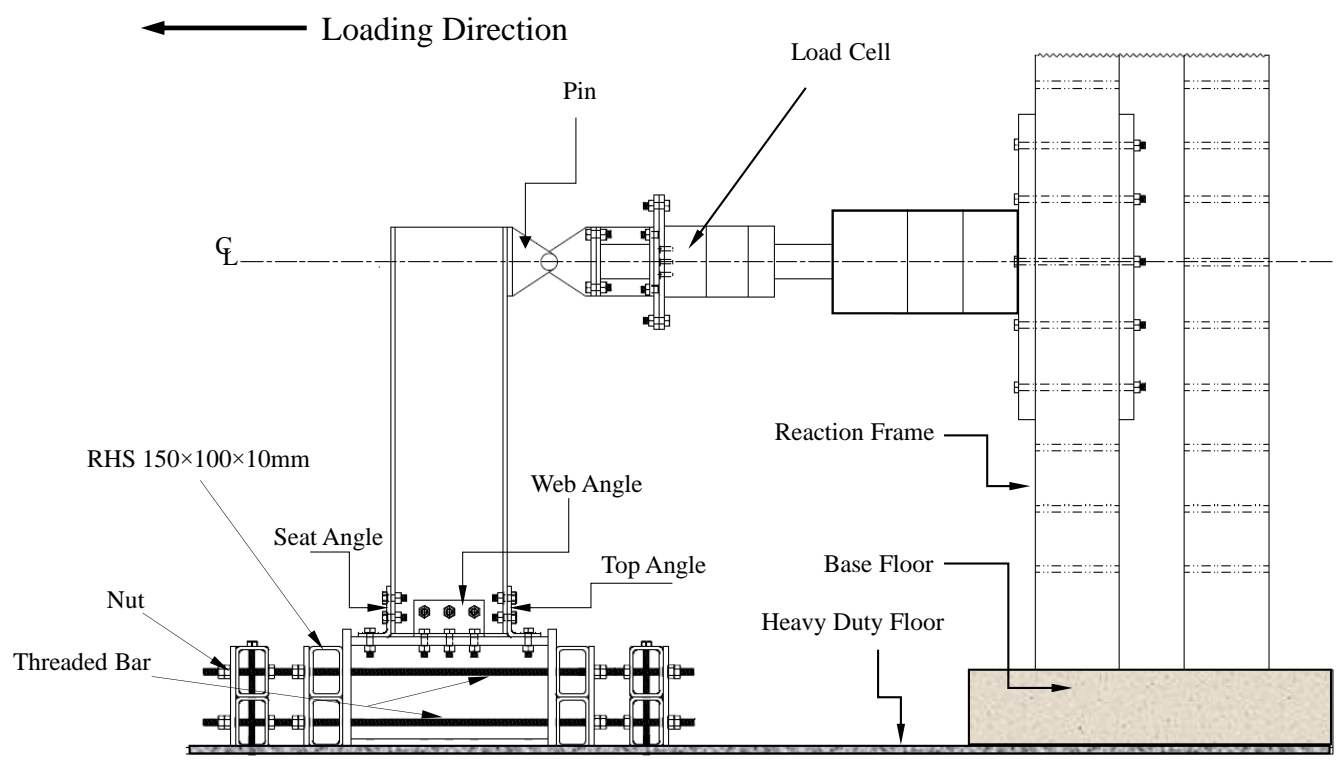

Fig. 7. Test setup showing restraining arrangement and load application.

\subsection{Top-seat with double web angle (TS-DWA) connection}

TS-DWA type connection is composed of four angles, which are used to connect both the flanges and the web of the beam to the column using bolts as fasteners. Connection components and configurations were taken to resemble, as much as possible, an earlier research on carbon steel beamcolumn connection [27, 29]. Built-up sections were formed using austenitic stainless steel plates to achieve geometric dimensions similar to the standard AISC sections W14×38 and W12×96, which were used as the beam and the column in the current study. Fig 6(a) shows the geometric details of the connection; a $600 \mathrm{~mm}$ long stub column was fixed at the base and a $1200 \mathrm{~mm}$ long beam was connected to the column using bolts to achieve TS-DWA connection arrangement. $150 \times 100 \times 12 \mathrm{~mm}$ angles were used as top seat to connect beam flanges to the column flange, whereas $100 \times 100 \times 10 \mathrm{~mm}$ web angles were used to connect the beam web to the column flange. Metric standard M20 austenitic grade bolts 
compliant with equivalent nut and washer were used as fasteners. Fig 6(b) shows all required geometric details of the TS-DWA connection type used in the current study.

\section{Test setup and instrumentation}

All considered beam-to-column connections were tested using the same loading arrangement in the Structures Laboratory at The University of New South Wales, Canberra, Australia. The schematic of the test setup used for TS-DWA connection is shown in Fig 7, where a monotonic load was applied to the free end of the beam to observe connection behaviour. The connection to be tested was placed between two bearing plates to restrain the column from any unwanted movement. The connection and the bearing plates were tightened by 8 rectangular hollow sections (RHS) with a cross-section of $150 \times 100 \times 10 \mathrm{~mm}$. RHSs were fastened by two layers of long-threaded $\phi 24 \mathrm{~mm}$ bar, which were 700 $\mathrm{mm}$ apart from each other. 6 long bolts of similar diameter were used to fix the whole arrangement to the strong floor. Necessary nuts and 8 small bearing plates $(150 \times 100 \times 10 \mathrm{~mm})$ were used to restrain the frame in the lateral direction. Uniform pressure was applied at the beam end using a loading fixture, in which a pin was placed parallel to the beam flange as illustrated in Fig 7. Connection moment was determined by multiplying the reaction force at the end of the beam with the lever arm calculated from the application of load at free end of the beam to the column face adjacent to the connection (Fig 7).

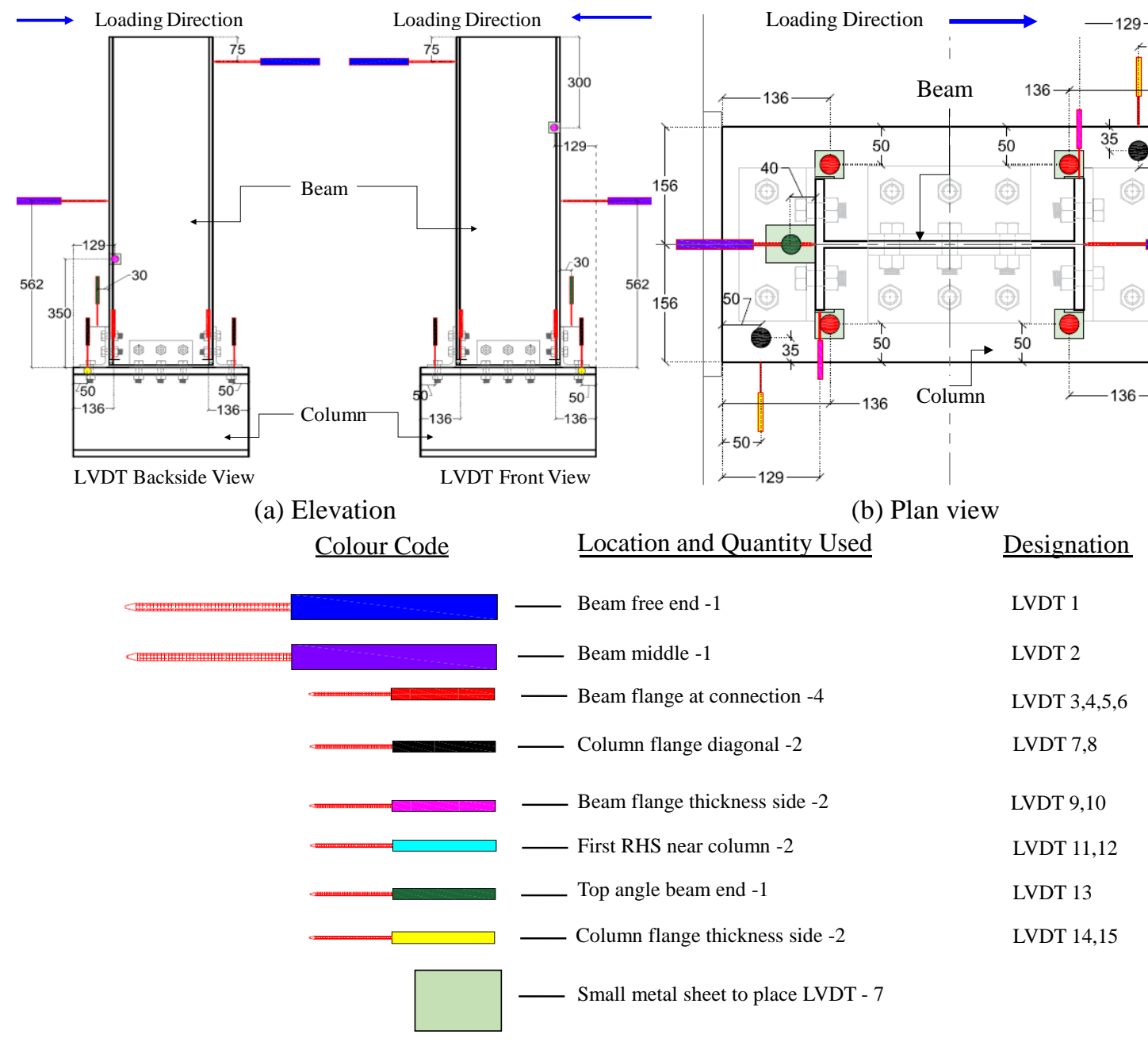

(c) LVDT designation

Fig. 8. LVDT installation scheme for data acquisition (all dimensions are in $\mathrm{mm}$ )

Loading was applied by using a $250 \mathrm{kN}$ Instron machine equipped with a special fixture mounted close to the free end of the beam at a distance of $1125 \mathrm{~mm}$ from the connection face. This fixture facilitated the transfer of lateral movement of the hydraulic ram to the beam while allowing the beam end to rotate as a result of the deformation occurring in the connection assembly. Testing was carried 
out using hydraulic actuator at a loading rate of $1 \mathrm{~mm} / \mathrm{min}$ for the first $15 \mathrm{~mm}$ of beam end displacement and later was increased to $3 \mathrm{~mm} / \mathrm{min}$ up to $50 \mathrm{~mm}$, and finally to a rate of $5 \mathrm{~mm} / \mathrm{min}$ until the test was stopped. All LVDTs were connected to the data logger to capture the load-deformation response of all connecting elements during the full loading regime. Both the DWA and TSA connections failed at their ultimate conditions i.e., the peak moment capacities were reached during the test condition before failure. However, the TS-DWA connection showed significant rotation and strength, and due to displacement restriction of the Instron machine, the test was stopped when the connection rotated around $127.4 \mathrm{mrad}$ and the beam free end moved $181.6 \mathrm{~mm}$ from its initial position due to the applied loading. The complete failure was, therefore, not achieved under experimental condition for this connection. Hence, the ultimate condition for TS-DWA connection in the current study refers to the case when the connection rotation reached $127.4 \mathrm{mrad}$.

\section{Material coupon tests}

Tensile coupon tests were performed to evaluate accurate material properties for the plate materials that were used to fabricate the considered beam and column sections resembling AISC sections W14×38 and W12 $\times 96$. Tension coupons were taken from the machining of the web angles, TS angles and bolts. The dimensions of all the tensile coupons were set according to relevant ISO standard [30]. All the tensile coupons were necked at the middle as shown in Fig 9(a) and (b). A submersible wire cutting technology was used to prepare the test coupons so as to minimize the heat effect during the cutting process. At least, three widths and three thickness measurements were taken using a digital vernier's calliper along the coupon necked length, and the average width and thickness values were used to calculate the cross-sectional area. Average results from three coupons for each of the web angles, TS angles and bolts are presented in Table 2 and Fig 10.

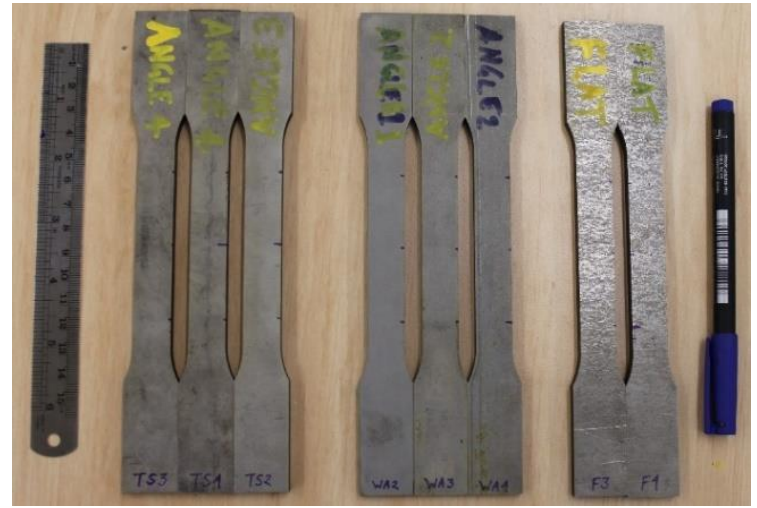

(a) flat coupon specimens (WA and TSA)

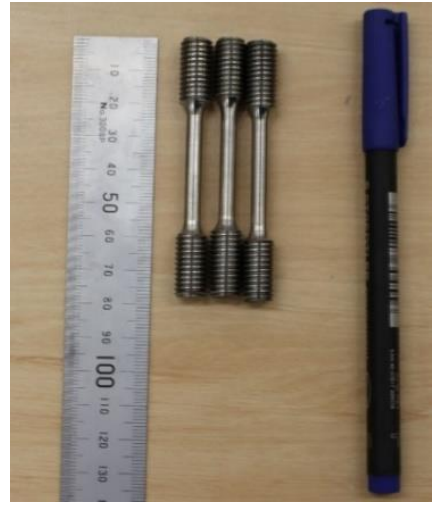

(b) round coupons (bolt)

Fig. 9. Tension test coupons according to EN ISO6892-1 (2009)

Shimadzu Z100 kN electromechanical universal testing machine (UTM) were utilized to perform all tensile coupon tests as shown in Fig 10, in accordance with EN ISO6892-1 [30]. To measure the longitudinal strain over a specified gauge length, video extensometer was used. Moreover, to record more accurate measurements for the initial elastic part of the stress-strain curves, a linear electrical resistance strain gauge was also attached to the face of each tensile coupon.

Table 2. Material properties of austenitic stainless steel plates used in the current study.

\begin{tabular}{lllllllll}
\hline $\begin{array}{l}\text { Connection } \\
\text { Element }\end{array}$ & $\begin{array}{l}t \text { or } d \\
(\mathrm{~mm})\end{array}$ & $\begin{array}{l}E \\
(\mathrm{MPa})\end{array}$ & $\begin{array}{l}\sigma_{0.2} \\
(\mathrm{MPa})\end{array}$ & $\begin{array}{l}\sigma_{1.0} \\
(\mathrm{MPa})\end{array}$ & $\begin{array}{l}\sigma_{\mathrm{u}} \\
(\mathrm{MPa})\end{array}$ & $\begin{array}{l}\varepsilon_{\mathrm{pl}, \mathrm{f}} \\
(\%)\end{array}$ & $n$ & $m$ \\
\hline Beam, Column & 5.76 & 199505 & 335 & 365 & 586 & 57.50 & 9.7 & 2.2 \\
Top-seat angle & 5.75 & 201338 & 326 & 361 & 602 & 54.29 & 9.8 & 2.3 \\
Web angle & 4.63 & 191535 & 278 & 310 & 566 & 59.62 & 6.3 & 2.5 \\
Bolt & 4.9 & 195380 & 470 & 517 & 639 & 10.37 & 4.5 & 3.8 \\
\hline
\end{tabular}

Key material parameters such as Young's modulus $E, 0.2 \%$ proof stress $\sigma_{0.2}$, ultimate tensile strength $\sigma_{\mathrm{u}}$ and Ramberg-Osgood (R-O) nonlinearity parameters $n$ and $m$ were extracted from the 
recorded stress-strain curves. The best fit Young's modulus $E$ was calculated based on the strain gauge measurements. Compound Ramberg-Osgood (R-O) nonlinearity parameters $\mathrm{n}$ and $\mathrm{m}$ were also calculated from the strain gauge data. Plastic strain at fracture $\varepsilon_{\mathrm{pl}, \mathrm{f}}$ was also measured. Results obtained from all tested coupons are summarized in Table 2. Stress-strain curves are shown in Fig 10.

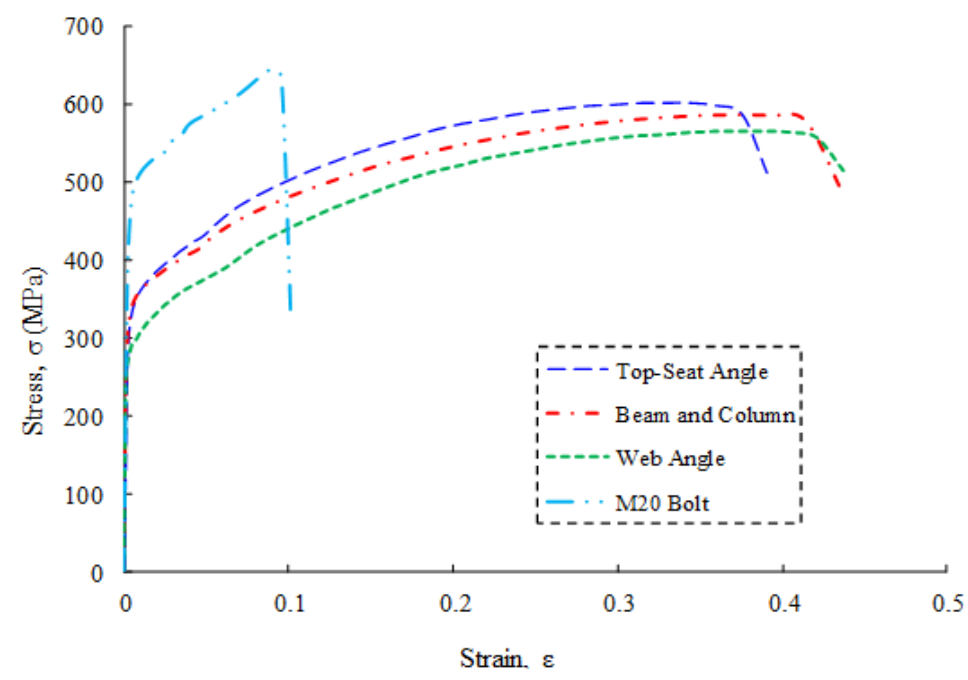

Fig. 10. Complete stress-strain curves of different stainless steel plates and bolt.

\section{$5 \mathrm{M}-\varphi$ behaviour of stainless steel beam-to-column connections}

\subsection{Measuring technique used to capture $M-\varphi$ response}

Accurate knowledge of connection $M$ - $\phi$ behaviour plays a crucial role is structural design of bare metallic frame structures. In this study, the connection rotations $\varphi$ were determined at three different sections as shown in Fig 11. Section 1-1 was considered at $35 \mathrm{~mm}$ away from the column face. Displacements $h_{1}$ and $h_{2}$ were taken from the left and the right flanges of the beam, and the connection rotation was calculated as $\varphi=\left(d_{1}-d_{2}\right) / h$; where, $\mathrm{h}$ is the beam depth and $d_{1}$ and $d_{2}$ are the measured displacements. Section 2-2 was considered along the centreline of web angle bolts, which was located $76 \mathrm{~mm}$ away from the column face, and the connection rotation was measured from the relative displacement of bolts along the section 2-2 as shown in Fig 11. Section 3-3 was considered along the beam centreline; the rotation of the connection was measured from the relative displacement of the free end of the beam with respect to the connected web angle at the intersection of section 1-1 and 3-3.

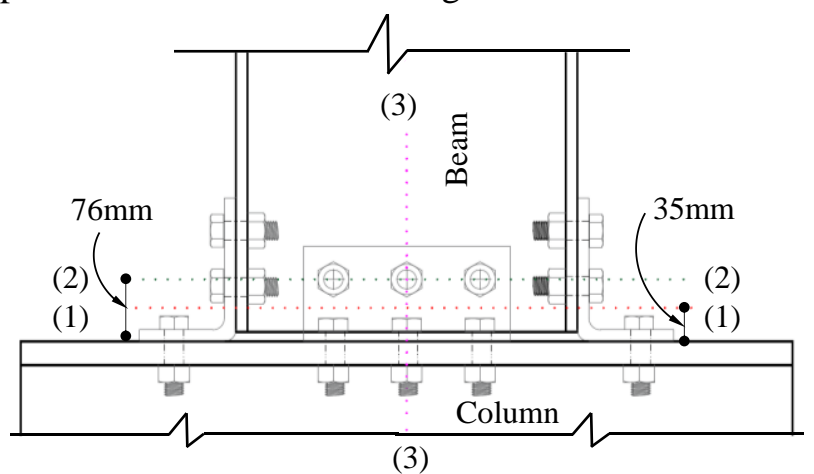

Fig. 11. Critical sections used in rotation measurement in the current experiment.

Fig 12 compares the $M-\phi$ behaviour of TS-DWA connection obtained from three techniques showing some minor differences among rotations measured at the considered 3 sections. Rotation measurements conducted along section 3-3 produced reduced initial stiffness but relatively higher moment carrying capacity for the connection. Rotation measurements along web bolt line i.e., section 2-2 produced the highest initial stiffness, but almost similar moment capacity as observed at section 11. This increased initial stiffness at section 2-2 was due to relatively smaller displacements experienced by the web bolts during the initial loading stage. However, very little differences were observed, overall, 
between the initial stiffness and the moment capacities obtained from three sections. Hence, the best-fit curve of three measurements was taken as the representative $M-\phi$ behaviour of the considered connection.

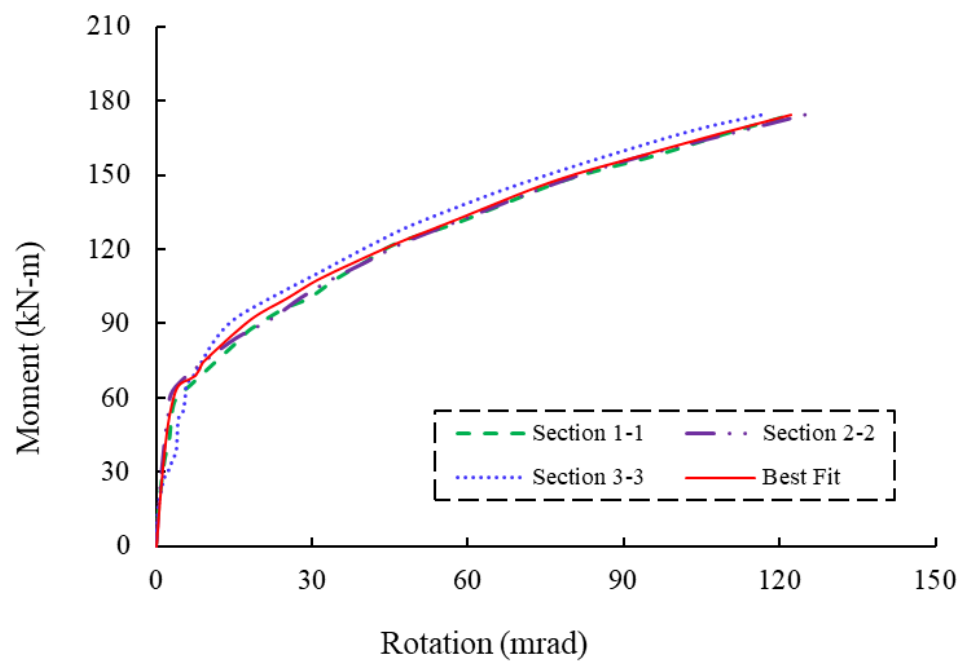

Fig. 12. M- $\varphi$ curves obtained from different methods of rotation measurement.

\subsection{M- $\varphi$ curves obtained for DWA, TSA and TS-DWA connections}

Fig 13 (a), (b) and (c) show the $M$ - $\phi$ curves obtained for DWA, TSA and TS-DWA connections considered in the current study along with those defined as the boundary lines for connections in Eurocode 3 [19], which defines connections by their stiffness or strength. As discussed in section 2, a connection is classified as rigid connection if the initial stiffness $K_{\mathrm{i}}>8 K_{\mathrm{b}}$ for braced frames or $K_{\mathrm{i}}>25$ $K_{\mathrm{b}}$ for unbraced frames. However, if $K_{\mathrm{i}} \leq 0.5 K_{\mathrm{b}}$, the connection is categorised as nominally pinned. Initial stiffness of a connection lying between these two extremes is classified as semi-rigid. Considering a typical low-rise residential building structure [28], the beam stiffness $K_{\mathrm{b}}$ was determined as $E I_{\mathrm{b}} / L_{\mathrm{b}}=4667 \mathrm{kN} . \mathrm{m} / \mathrm{rad}$. Hence, in the current study, Eurocode 3 specified boundaries for initial stiffness $\mathrm{K}_{\mathrm{i}}$ may be taken as $25 E I_{\mathrm{b}} / L_{\mathrm{b}}=116,676 \mathrm{kN} . \mathrm{m} / \mathrm{rad}$ and $0.5 E I_{\mathrm{b}} / L_{\mathrm{b}}=2333 \mathrm{kN} . \mathrm{m} / \mathrm{rad}$.

Initial stiffness $\mathrm{K}_{\mathrm{i}}$ for DWA, TSA and TS-DWA were determined from their $M-\phi$ curves, as shown in Fig. 13, which were 1685, 9865 and 29244 kN-m/rad, respectively. Obtained test results show that DWA connections can be treated as a pinned connection whilst TSA and TS-DWA connections fall within the semi-rigid category. Use of TS angles can significantly enhance the moment resisting capacity of beam-to-column connection in stainless steel frames. TS angles specifically provide significant bearing to the beam and enhance the moment transfer capacity of the connection.

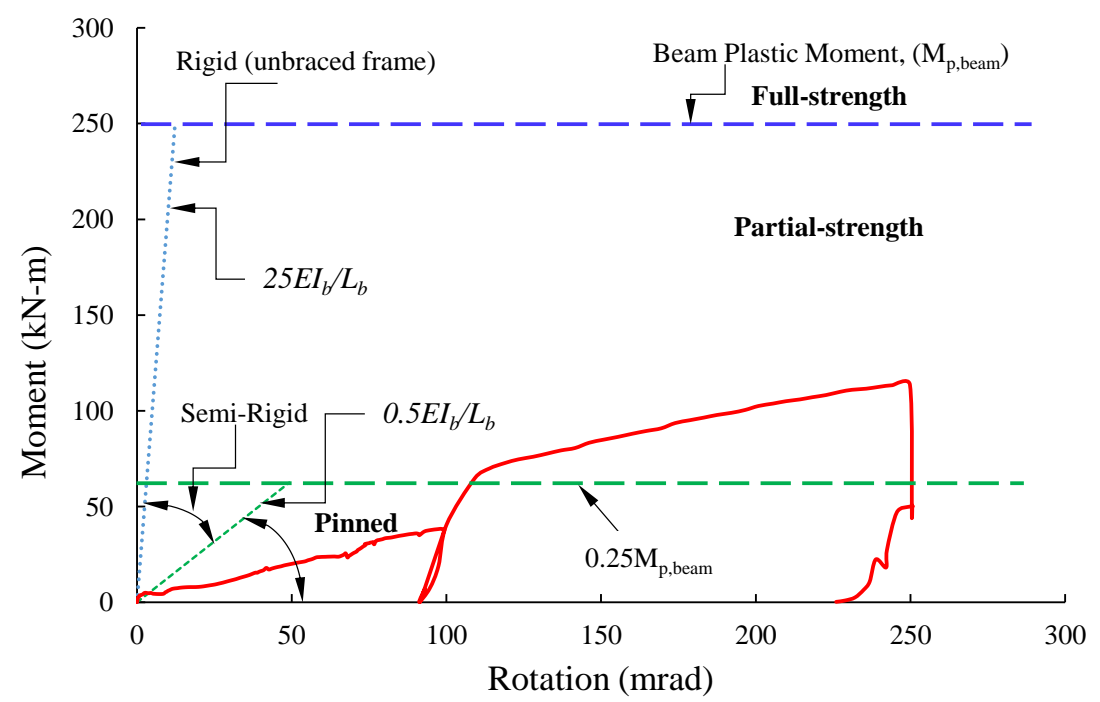

(a) $\mathrm{M}-\varphi$ response and classification for stainless steel DWA (double web angle) connection

000002-10 
Ashraf et al, SUST, 2021, 1(1): 000002

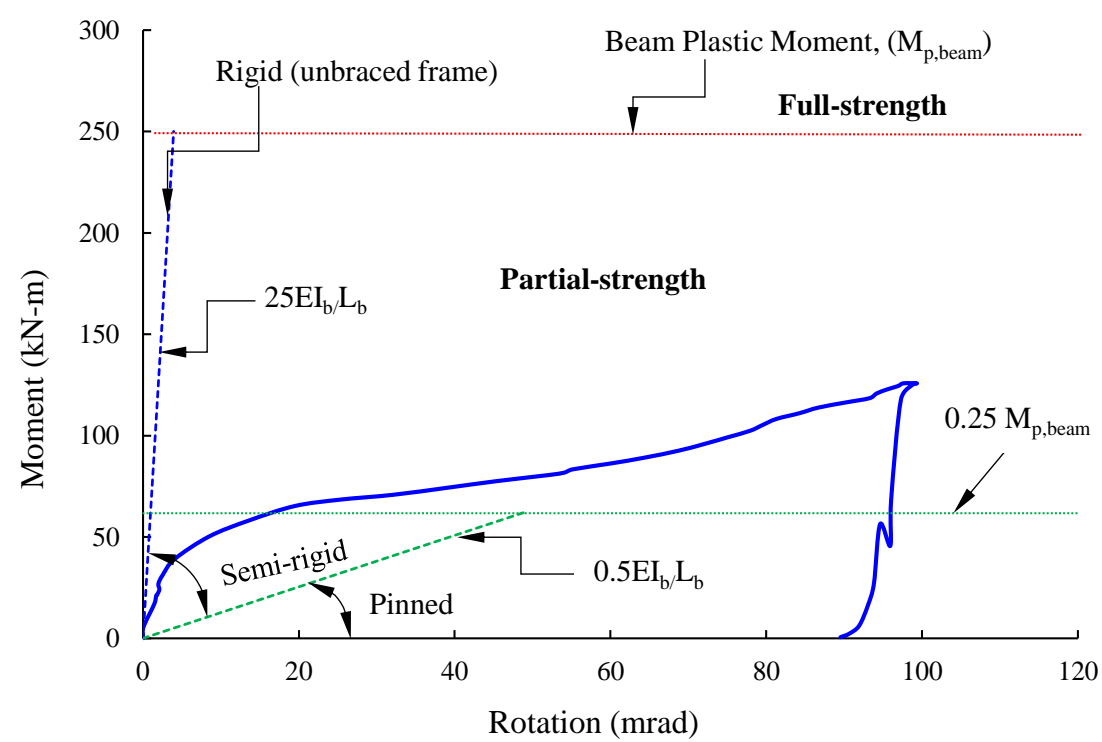

(b) M- $\varphi$ response and classification for stainless steel TSA (top seat angle) connection

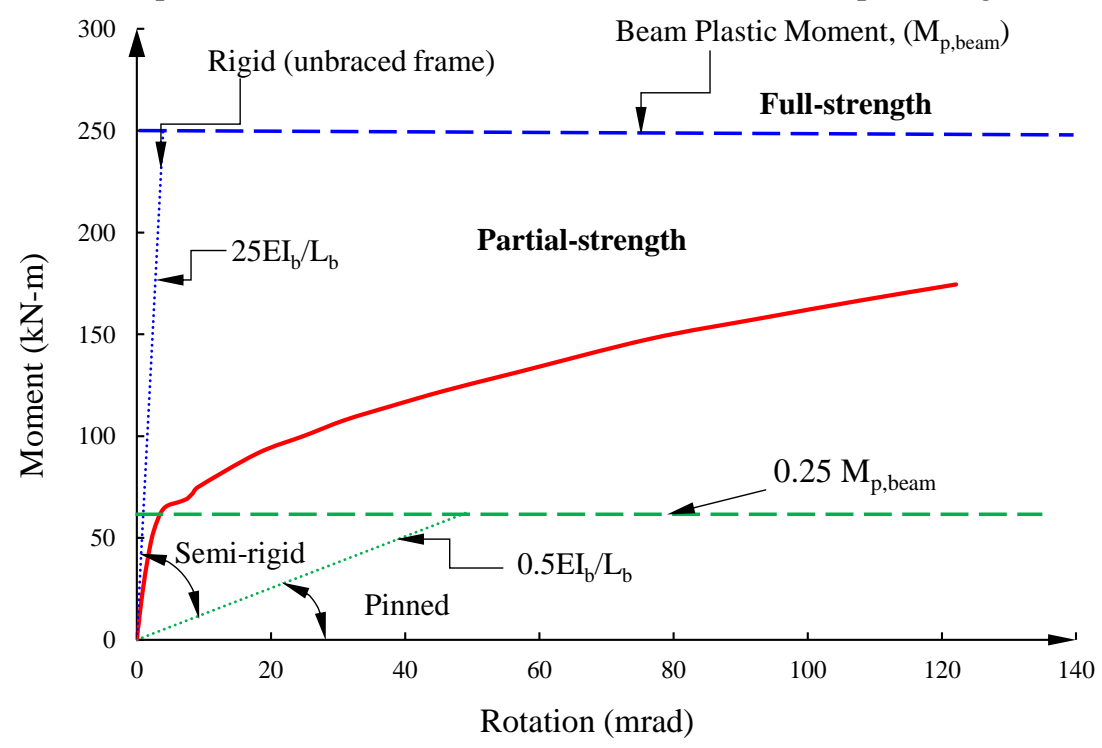

(c) M- $\varphi$ response and classification for stainless steel TS-DWA (top seat with double web angle) connection

Fig. 13. $M-\varphi$ characteristics of stainless steel connections according to Eurocode 3.

\subsection{Deformations and rotational characteristics observed in stainless steel connections}

In addition to the initial stiffness $K_{\mathrm{i}}$ of a connection, Eurocode 3 [19] specifies three types of connections based on the ultimate moment capacity $\mathrm{M}_{\mathrm{u}}$ of a connection. A connection is classified as "full-strength" if $M_{\mathrm{u}} \geq M_{\mathrm{p}}$, beam (plastic moment capacity of the beam), whereas if $M_{\mathrm{u}} \leq 0.25 M_{\mathrm{p}}$, beam, the connection is classified as "nominally pinned". When $M_{\mathrm{u}}$ of a connection lies between $0.25 M_{\mathrm{p}}$, beam and

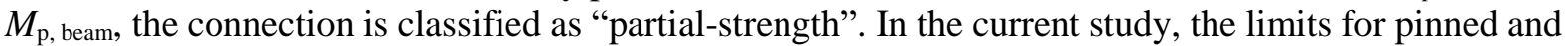
full strength connections were $62.5 \mathrm{kN} . \mathrm{m}$ and $250 \mathrm{kN}$.m, respectively, based on the beam geometry and the material strength for the austenitic stainless steel grade used for fabricating test specimens. Moment capacities measured at $20 \mathrm{mrad}$ rotation $M_{20 \mathrm{mard}}$ for DWA, TSA and TS-DWA connections were 6.84 kN.m (pinned connection), $65.55 \mathrm{kN} . \mathrm{m}$ (partial strength connection) and $91.66 \mathrm{kN} . \mathrm{m}$ (partial strength connection). This clearly shows that DWA stainless steel connections considered in the current study failed to meet the criteria for semi-rigid or partial strength connections whereas TSA and TS-DWA connections showed sufficient stiffness and strength to be classified as semi-rigid behaviour.

Connection rotation capacity is essential to satisfy the serviceability criteria, structural ductility and distribution of internal forces. Eurocode 3 [19] considers only the behaviour of a connection at the ultimate limit states and does not explicitly consider the serviceability criteria. FEMA 350 [31] specifies 
Ashraf et al, SUST, 2021, 1(1): 000002

that a minimum connection rotation of $30 \mathrm{mrad}$ as a requirement for earthquake design of ordinary moment frames. It is worth noting that all considered stainless steel connections clearly met this criterion for serviceability highlighting the impact of high ductility of austenitic stainless steel.

Figure 14 (a), (b) and (c) show the deformed shapes of DWA, TSA and TS-DWA connections at failure or when the test was stopped due to excessive deformations. It was observed that one of the bolts in DWA connection failed due to shear, which caused a sudden drop in $M-\phi$ response as shown in Fig 13(a). However, the connection still kept deforming without any abrupt failure of any bolt or connecting angles due to the high ductility of austenitic stainless steel.

\section{Summary of observations from stainless steel connection tests}

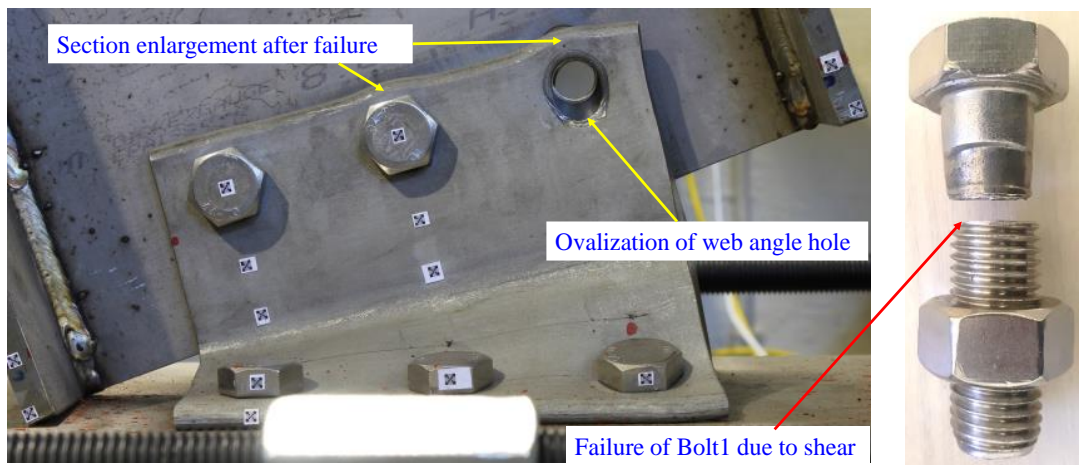

(a) Deformations observed in DWA connection showing shear failure of bolt

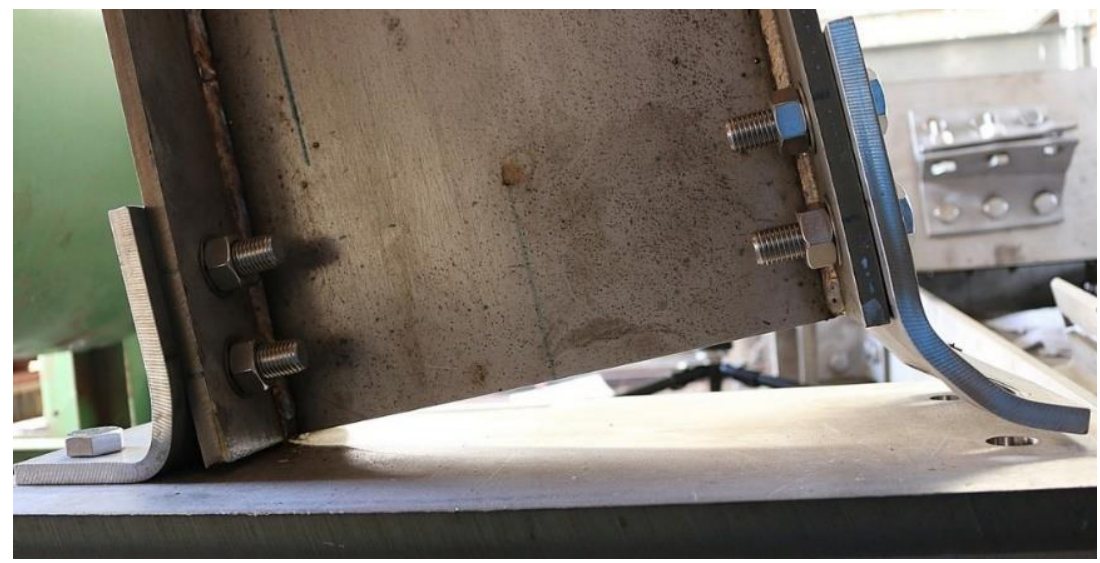

(b) Deformations observed in TSA connection showing tension failure of bolts.

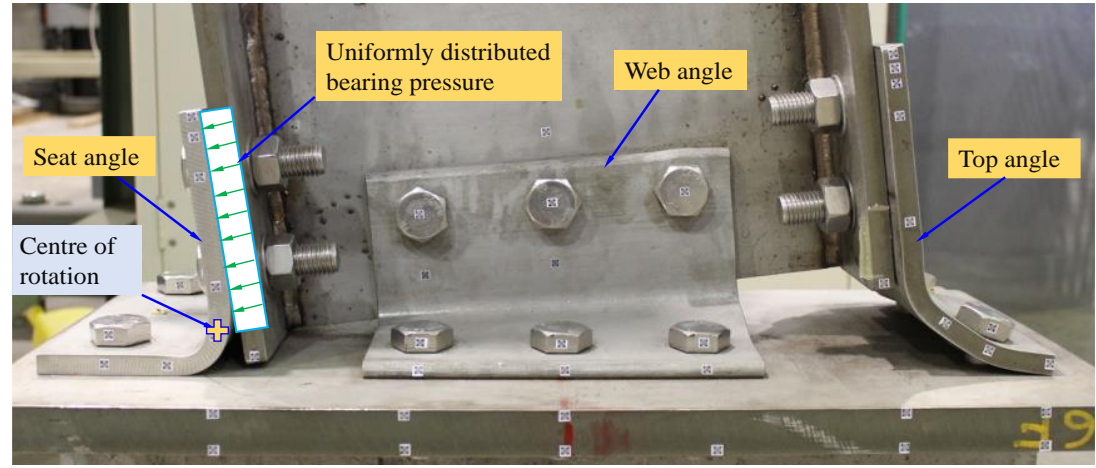

(c) Deformations observed in TS-DWA connection when the test was stopped (no obvious failure).

Fig. 14. Deformations observed in stainless steel beam-to-column connections.

Deformations of various connecting elements for all considered beam-to-column connection were carefully recorded and analysed [21] revealing that TSA connections, with or without DWA, rotated at a critical section of the seat angles; significant plastic deformations were observed in the top angle as well as in connecting bolts. Part of the top angle that was attached to the beam flange behaved like a rigid body whereas the other part of the top angle that was on the column side was flattened and 
deformed significantly. Seat angle carried the bearing pressure uniformly through the legs attached to the beam flange. Plastic hinges developed on the top angle in the vicinity of bolt rows in column flanges and at the junction of the angle's beam-column leg. On the other hand, DWA connection, which is typically assumed to carry only the shear force through the bolt assembly, also deformed significantly and noticeable bolt slippages were observed at the initial stage of loading. Whilst the web angle leg attached to the beam acted as rigid parts, the other leg connected to the column suffered significant plastic deformations. Due to gradual increase in loading, substantial enlargement was experienced in the vicinity of the web angle top bolt creating ovalization of bolt holes as shown in Fig 14(a).

Study of failure mechanism in the current experimental investigation demonstrated that failure primarily occurred after gradual yielding and severe necking at the bolt section. In the case of TSA connection, bolt attached to the top angle and column flange failed at the ultimate condition due to combination of bending and tensioning of top bolts. Similar failure characteristics were obtained for TS-DWA connection, although the test was stopped prior to complete failure. Failure in the DWA connection occurred in the top beam bolt due to shearing of the bolt section. Overall, in all tested connection specimens, failure was limited by the connecting bolts due to the low ductility of the bolts compared to the high ductility exhibited by all other stainless steel connection components. Strain distributions in the connection confirmed that top and seat angles were more capable of transmitting bending resistance than the web angles.

\section{Conclusions}

Experimental investigations on the moment-rotation $(M-\phi)$ behaviour of three typical full scale stainless steel beam-to-column connections such as double web angle (DWA), top seat angle (TSA) and top seat with double web angle (TS-DWA) are presented in the current paper. These connection types are widely used in bare metallic construction, especially in ordinary steel construction, and significant research has been reported on connections produced from carbon steel. Full scale tests on such connections produced from stainless steel are scarce albeit their importance for promoting use of stainless steel in structural applications. All connection elements were manufactured from austenitic stainless steel, and M20 grade high strength bolts were used to form the connection assemblies. $M-\phi$ curves obtained for DWA, TSA and TS-DWA connections were used to determine their initial stiffness $K_{\mathrm{i}}$ and moment capacities at $20 \mathrm{mrad} M_{20 \mathrm{mrad}}$ to check against connection classifications recommended by Eurocode 3. The considered DWA connection performed within the category of pinned connection due to its low $K_{\mathrm{i}}=6.84 \mathrm{kN}$.m, which was well below $0.25 K_{\mathrm{b}}(=62.5 \mathrm{kN} . \mathrm{m})$ threshold to warrant recognition as a semi-rigid connection. The moment capacity of DWA connection was also well under the limit for partial strength connection as recommended by Eurocode 3. DWA connection failed due to shear failure in one of bolts but still showed significant ductility and easily surpassed the minimum connection rotation of $30 \mathrm{mrad}$ as a requirement for earthquake design of ordinary moment frames recommended by FEMA. TSA connections, on the other hand, showed a remarkable increase in both $K_{\mathrm{i}}$ and $M_{20 \mathrm{mrad}}$ and, hence, can be considered as a semi-rigid connection. Top and seat angles were more effective in resisting bending moments when compared against that by the alternative angle assembly arrangement in DWA connections. When top-seat angle and double-web angles were combined in TSDWA connection assembly, the connection performance enhanced by a significant margin both in terms of $K_{\mathrm{i}}$ and $M_{20 \mathrm{mrad}}$. All the considered connections easily surpassed the minimum serviceability criteria recommended by FEMA highlighting the benefit of extensive ductility of stainless steel.

\section{References}

[1] Lui EM, Ashraf M, Young B. Tests of cold-formed duplex stainless steel SHS beam-columns. Engineering Structures 2014; 74; 111-121. https://doi.org/10.1016/j.engstruct.2014.05.009.

[2] Anbarasu M, Ashraf M. Behaviour and design of cold-formed lean duplex stainless steel lipped channel columns. Thin-walled structures 2016; 104; 106-115. https://doi.org/ 10.1016/j.tws.2016.03.012.

[3] Theofanous M, Gardner L. Experimental and numerical studies of lean duplex stainless steel beams. Journal of Constructional Steel Research 2010; 66(6): 816-825. https://doi.org/ 10.1016/j.jcsr.2010.01.012.

[4] Gardner L. The use of stainless steel in structures. Progress in Structural Engineering and Materials $2005 ; 7$ (2): 45-55. https://doi.org/10.1002/pse.190.

[5] Anwar-Us-Saadat M, Ashraf M, Ahmed M. Behaviour and design of stainless steel slender cross-sections 
Ashraf et al, SUST, 2021, 1(1): 000002

subjected to combined loading. Thin-Walled Structures 2016; 104; 225-237. https://doi.org/10.1016/j.tws.2 016.03.020.

[6] Ahmed S, Ashraf M. Numerical investigation on buckling resistance of stainless steel hollow members. Journal of Constructional Steel Research 2017; 136; 193-203. https://doi.org/ 10.1016/j.jcsr.2017.05.017.

[7] Anwar-Us-Saadat M, Ashraf M. The continuous strength method for lateral-torsional buckling of stainless steel I-beams. Thin-Walled Structures 2018; 130; 148-160. https://doi.org/ 10.1016/j.tws.2018.05.017.

[8] Ahmed S, Al-Deen S, Ashraf M. Design rules for stainless steel welded I-columns based on experimental and numerical studies. Engineering Structures 2018; 172; 850-868. https://doi.org/10.1016/j.engstruct.2018. 06.080 .

[9] Ahmed S, Ashraf M, Anwar-Us-Saadat M. The Continuous Strength Method for slender stainless steel crosssections. Thin-Walled Structures 2016; 107; 362-376. https://doi.org/ 10.1016/j.tws.2016.06.023.

[10] Bouchaï A, Averseng J, Abidelah A. Analysis of the behaviour of stainless steel bolted connections. Journal of Constructional Steel Research 2008; 64(11): 1264-1274. https://doi.org/ 10.1016/j.jcsr.2008.07.009.

[11] Averseng J, Bouchaïr A. Modelling and analysis of bolted stainless steel cover plate joints. European Journal of Environmental and Civil Engineering 2011; 13(4): 443-456. https://doi.org/10.1080/19648189.2009.9693 122.

[12] Kim TS, Kuwamura H, Cho TJ. A parametric study on ultimate strength of single shear bolted connections with curling. Thin-Walled Structures 2008; 46(1): 38-53. https://doi.org/ 10.1016/j.tws.2007.08.009.

[13] Salih EL, Gardner L, Nethercot DA. Bearing failure in stainless steel bolted connections. Engineering Structures 2011; 33(2): 549-562. https://doi.org/ 10.1016/j.engstruct.2010.11.013.

[14] Nethercot DA, Salih EL, Gardner L. Behaviour and Design of Stainless Steel Bolted Connections. Advances in Structural Engineering 2011; 14(4): 647-658.

[15] Salih EL, Gardner L, Nethercot DA. Numerical investigation of net section failure in stainless steel bolted connections. Journal of Constructional Steel Research 2010; 66(12): 1455-1466. https://doi.org/10.0161/ j.jcsr.2010.05.012.

[16] Hasan MJ, Ashraf M, Uy B. Moment-rotation behaviour of top-seat angle bolted connections produced from austenitic stainless steel. Journal of Constructional Steel Research 2017; 136; 149-161. https://doi.org/ 10.1016/j.jcsr.2017.05.014.

[17] Hasan MJ, Al-Deen S, Ashraf M. Behaviour of top-seat double web angle connection produced from austenitic stainless steel. Journal of Constructional Steel Research 2019; 155; 460-479. https://doi.org/ 10.1016/j.jcsr.2018.12.015.

[18] Elflah M, Theofanous M, Dirar S, et al. Behaviour of stainless steel beam-to-column joints - Part 1: Experimental investigation[J]. Journal of Constructional Steel Research, 2019, 152: 183-193.https://doi.org/ 10.1016/j.jcsr.2018.02.040.

[19] EN1993-1-8, Eurocode 3: Design of steel structures, Part 1-8: Design of joints, European Standard CEN 2005, Brussels, Belgium, 2005.

[20] Song Y, Wang J, Uy B, Li D. Experimental behaviour and fracture prediction of austenitic stainless steel bolts under combined tension and shear. Journal of Construction Steel Research 2020. 166; 105916. https://doi.org/ 10.1016/j.jcsr.2019.105916.

[21] Hasan MJ. Semi-rigid behaviour and design of stainless steel bolted connections. Australian Defence Force Academy, 2019.

[22] Specifications for Structural Steel Buildings, American Institution of Steel Construction, Chicago, IL, 2010.

[23] Goverdhan A V. A collection of experimental moment-rotation curves and evaluation of prediction equations for semi-rigid connections. Vanderbilt University, 1983.

[24] Kishi N, Chen W F. Data base of steel beam-to-column connections. Structural Engineering Area, School of Civil Engineering, Purdue University, 1986.

[25] Ang KM, Morris GA. Analysis of three-dimensional frames with flexible beam-column connections. Canadian Journal of Civil Engineering 1984; 11; 245-254. https://doi.org/ 10.1139/184-037.

[26] Azizinamini A, Radziminski JB. Static and Cyclic Performance of Semirigid Steel Beam-to-Column Connections. Journal of Structural Engineering 1989; 115; 2979-2999. https://doi.org/10.1061/ (ASCE) 0733-9445(1989)115:12(2979).

[27] Azizinamini A, Bradburn J H, Radziminski J B. Static and cyclic behavior of semi-rigid steel beam-column connections. University of South Carolina, 1985

[28] Azizinamini A, Bradburn JH, Radziminski JB. Initial stiffness of semi-rigid steel beam-to-column connections. Journal of Constructional Steel Research 1987; 8; 71-90. https://doi.org/ 10.1016/0143-974X (87)90054-X.

[29] ISO E N. 6892-1. Metallic materials-Tensile testing-Part 1: Method of test at room temperature. International Organization for Standardization, 2009.

[30] FEMA F. Recommended seismic design criteria for new steel moment-frame buildings. FEMA-350, 2000. 